\title{
Obtaining sustenance through spirits
}

A fter not eating for up to 11 days and working out four hours daily, Damian Mangat, then 16 years old, was still dissatisfied with her weight when she came across a novel proposition. While part of an outpatient program at a hospital in Toronto, she met a slender girl who disclosed her technique for keeping thin: drink alcohol while consuming no food.

Mangat decided to give it a try. "I thought 'perfect, I already love to drink when I can get it, and now I won't have to worry about the dizziness because now when I need energy I can just take a shot of something,," she says. "It seemed to work. It seemed to be the magic answer for me."

Such a coupling of an eating disorder with alcohol abuse has been coined "drunkorexia."

Mangat, now 40 and a mature student at a university in Toronto, says the practice is common among college-age women and she often hears talk of forgoing food to save calories for alcohol.

"The thinking is first of all, I'll save the calories," she says. "Secondly, I'll get drunk on less and I'll look good in what I'm wearing, and then later if I do end up eating, I can always throw it up because the booze makes it easy to throw it up."

Drunkorexia is not recognized in any clinical inventory but shares poppsychology status with a number of other troublesome behaviours such as orthorexia (an extreme preoccupation with eating foods perceived to be healthy and avoiding foods that are not), manorexia (the male version of anorexia nervosa) and bridorexia (when a bride-to-be fasts to ensure she can fit into a certain size dress).

The typical person with drunkorexia is often cast as a young, female postsecondary student, prone to binge drinking because of the pressures of university life and a preoccupation with body image.

But males are not impervious to eating disorders and by extension drunkorexia, as more and more college-age men are concerned with their looks and marketability on the party scene, says Sondra Kronberg, a spokesperson for the National Eating Disorders Association and a clinical nutrition therapist based in Long Island, New York.

Behaviour associated with drunkorexia is more consistent with that demonstrated by people with bulimia, rather than anorexia, because the former more typically involves "compensation," Kronberg says.

Monitoring what one eats and deliberately restricting caloric intake from food to allow for the consumption of beverages are probably part of dietconscious eating, but problems occur when these behaviours are mixed, she

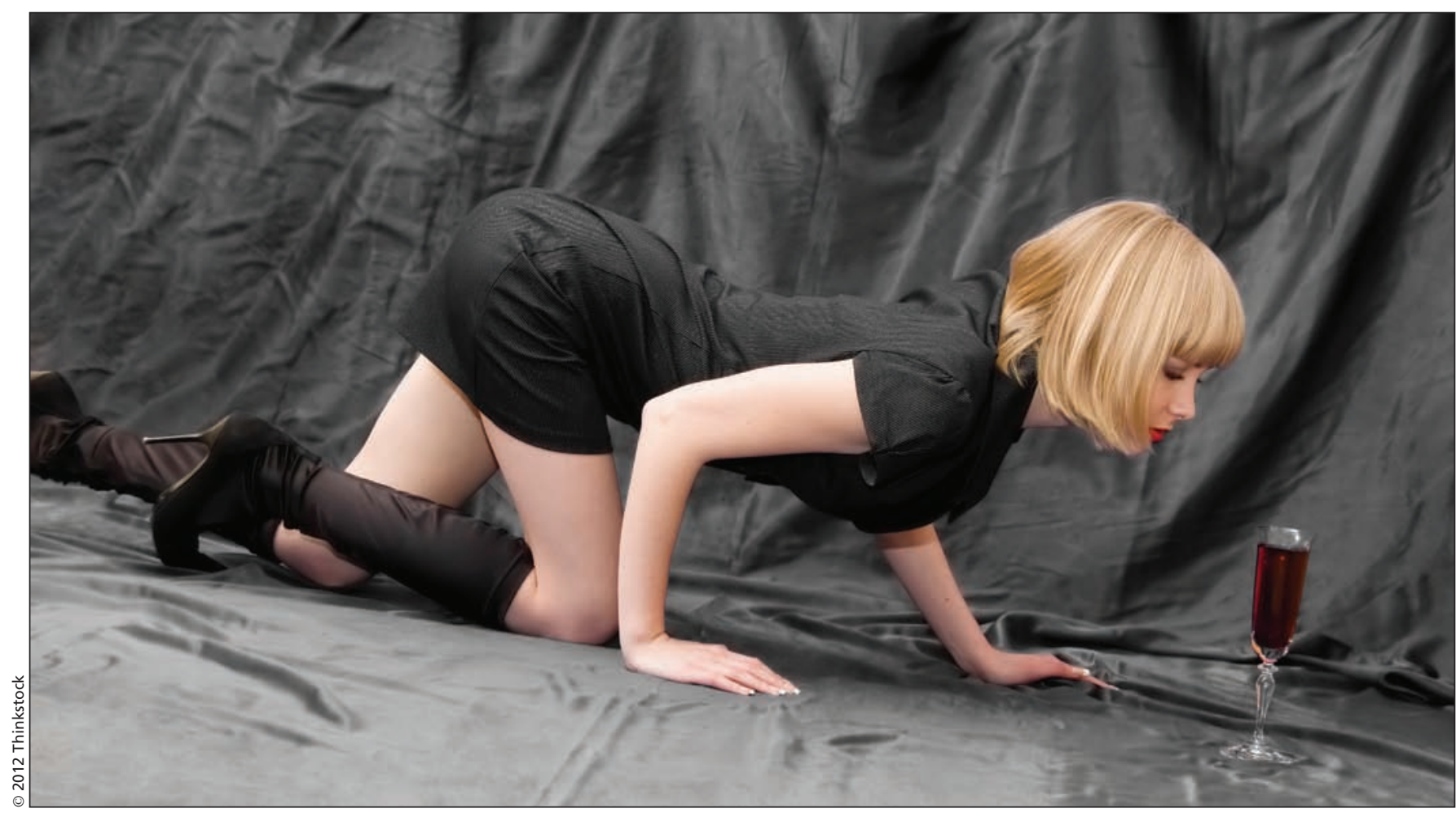

The typical person with drunkorexia is often cast as a young, female post-secondary student, prone to binge drinking because of the pressures of university life and a preoccupation with body image. 
adds. "The severity of it becomes when somebody with the potential for an eating disorder who is severely malnourished and restricting and underfed then goes on the weekend and just consumes alcohol. That's a potential cocktail for disaster. The idea that we're talking about this already life-threatening disorder - an eating disorder whether it be anorexia or bulimia - then being complicated with this added risk of alcohol is really significantly increasing the potential fatalities the disorder can take."

Although hard figures on the prevalence of drunkorexia are difficult to obtain, a survey of 695 first-year students in the United States found that 99 (14\%) deliberately refraining from eating prior to drinking ( $\mathrm{J}$ Alcohol Drug Educ Aug. 2010; 54. Available at, http://findarticles.com/p/articles/mi_go 2545/is_2_54/ai_n55140635/). Some $6 \%$ of participants reported a desire to avoid weight gain as their motivation for drunkorexic behaviour, while $10 \%$ wished to enhance the effects of alcohol.

That women are more prone to behaviour associated with drunkorexia is particularly troubling as they are more vulnerable than men to the consequences of excessive alcohol consumption, the authors added. "Women gener- ally weigh less, have less alcohol metabolizing enzymes (alcohol dehydrogenase), and typically have less total body water to dilute alcohol in the blood." Metabolic differences also leave women more susceptible to alcohol-related health conditions like cirrhosis and brain damage, stated the authors, although they were careful to stress that drinking on an empty stomach is not a good idea for either sex as it allows alcohol to enter the body faster, raises blood alcohol levels and increases health risks.

Despite increased publicity, it's unclear whether drunkorexia is worthy of formal recognition as an eating or mental disorder, says Dr. Andrew Chambers, an associate professor of psychiatry at the University of Indiana School of Medicine in Bloomington. But it may be a comorbidity of addiction and mental illness, he adds. "There are so many different permutations of how dual diagnosis can happen. If we go about literally formulating each one of those permutations as its own disorder, we're not going to see the forest for the trees."

But clinicians should approach it from that dual perspective, Chambers argues. "Like is often the case, addictions don't happen in isolation, they happen in comorbidity with mental illness," he says, adding that research suggests that a focus on just one aspect doesn't yield much in the way of clinical progress.

"Our society as a whole is really very ill-equipped to handle the combination," Chambers adds. "We seem to have invested all of our research infrastructure, all of our clinical services, the way we train professionals, in the notion that mental illnesses and addictions are very separate phenomena when in fact they are not."

It's also important for clinicians to begin taking the condition seriously, Mangat says. "Yes, drunkorexia has hit the media and it's always 'drunkorexia' in big capital letters and there's always references to some celebrity or something. I think they need to treat it the same way they would treat someone with schizophrenia, AIDS, or with any disorder."

"The title itself does not help people come out," she adds. "Do you want people to come out now and say 'I'm a drunkorexic?' I think there needs to be some professionalism in this." Michael Monette, Ottawa, Ont.

CMAJ 2012. DOI:10.1503/cmaj.109-4146 